EPSC Abstracts

Vol. 14, EPSC2020-590, 2020

https://doi.org/10.5194/epsc2020-590

Europlanet Science Congress 2020

(C) Author(s) 2021. This work is distributed under

the Creative Commons Attribution 4.0 License.

\title{
Isotopic composition of water vapour in the Martian atmosphere: vertical profiles from ACS MIR on ExoMars TGO
}

\author{
Juan Alday ${ }^{1}$, Patrick G. J. Irwin ${ }^{1}$, Colin F. Wilson ${ }^{1}$, Kevin S. Olsen ${ }^{1}$, Lucio Baggio ${ }^{2}$, Franck \\ Montmessin'2, Oleg Korablev ${ }^{3}$, Alexander Trokhimovskiy ${ }^{3}$, Anna A. Fedorova ${ }^{3}$, Denis A. Belyaev ${ }^{3}$, \\ Alexey Shakun ${ }^{3}$, Andrew Patrakeev ${ }^{3}$, and Alexey Grigoriev ${ }^{3}$ \\ ${ }^{1}$ University of Oxford, Atmospheric, Oceanic and Planetary Physics, Atmospheric, Oceanic and Planetary Physics, Oxford, United \\ Kingdom of Great Britain and Northern Ireland (juan.aldayparejo@physics.ox.ac.uk) \\ ${ }^{2}$ LATMOS/CNRS, Paris, France. \\ ${ }^{3}$ Space Research Institute (IKI), Moscow, Russia
}

\begin{abstract}
We report retrievals in the $2.53-2.79 \mu \mathrm{m}$ spectral range using the Atmopheric Chemistry Suite onboard of ExoMars Trace Gas Orbiter, which allow the simultaneous measurement of vertical profiles of $\mathrm{H}$ and $\mathrm{O}$ isotope ratios in water vapour in the Martian atmosphere. The large coverage of ACS MIR solar occultations provides the possibility to analyse the spatial, seasonal and diurnal variations of these ratios.
\end{abstract}

\section{Introduction}

Isotopic ratios in $\mathrm{C}, \mathrm{O}$ and $\mathrm{H}$ provide important clues to understand the history and evolution of volatiles on Mars. Enrichment of the D/H ratio by a factor of approximately 5.5 in atmospheric water vapour with respect to the Vienna Standard Mean Ocean Water [1] has often been understood as evidence of the substantial atmospheric escape into space.

On the other hand, oxygen isotope ratios in both water vapour and carbon dioxide do not show substantial enrichment of the heavier isotopes (e.g. [2],[3]). The lack of substantial fractionation therefore indicates the presence of a large reservoir of oxygen to exchange with the atmosphere [4].

In this work, we use solar occultation measurements made with the mid-infrared (MIR) channel of the Atmospheric Chemistry Suite (ACS), onboard ExoMars Trace Gas Orbiter (TGO) to measure the evolution of the vertical structure of the isotopic composition of water vapour $\left(\mathrm{D} / \mathrm{H},{ }^{18} \mathrm{O} /{ }^{16} \mathrm{O}\right.$ and ${ }^{17}$ $\mathrm{O} /{ }^{16} \mathrm{O}$ ) at the terminator for a full Martian year.

\section{Measurements}

ACS consists of a set of three infrared spectrometers covering a total wavelength range from 0.7 to $17 \mu \mathrm{m}$. The MIR channel, used in this study, is a cross-dispersion echelle spectrometer dedicated to solar occultation measurements in the $2.3-4.2 \mu \mathrm{m}(2300-4400 \mathrm{~cm}-1)$ range, with the main objective of measuring high resolution spectra $(\lambda / \Delta \lambda \square 30000-50000)$ in a wide instantaneous spectral range (width $0.15-0.3 \mu \mathrm{m}$ ). In order to cover the full spectral range, MIR is equipped with a steerable 
secondary grating that allows the selection of different diffraction orders [5].

In this work, we analyse MIR spectra in secondary grating positions 4 and 5 , which allow the simultaneous measurement of several diffraction orders covering a spectral range from 2.67 to $2.79 \mu \mathrm{m}(3584-3745 \mathrm{~cm}-1)$ and 2.53 to $2.67 \mu \mathrm{m}(3745-3952 \mathrm{~cm}-1)$, respectively. We select spectral windows in several diffraction orders, which show absorption lines of the four main oxygen isotopologues of water vapour $\left(\mathrm{H}_{2}{ }^{16} \mathrm{O}, \mathrm{H}_{2}{ }^{18} \mathrm{O}, \mathrm{H}_{2}{ }^{17} \mathrm{O}, \mathrm{HD}^{16} \mathrm{O}\right.$ ) and $\mathrm{CO}_{2}$ (see Figure 1 ).
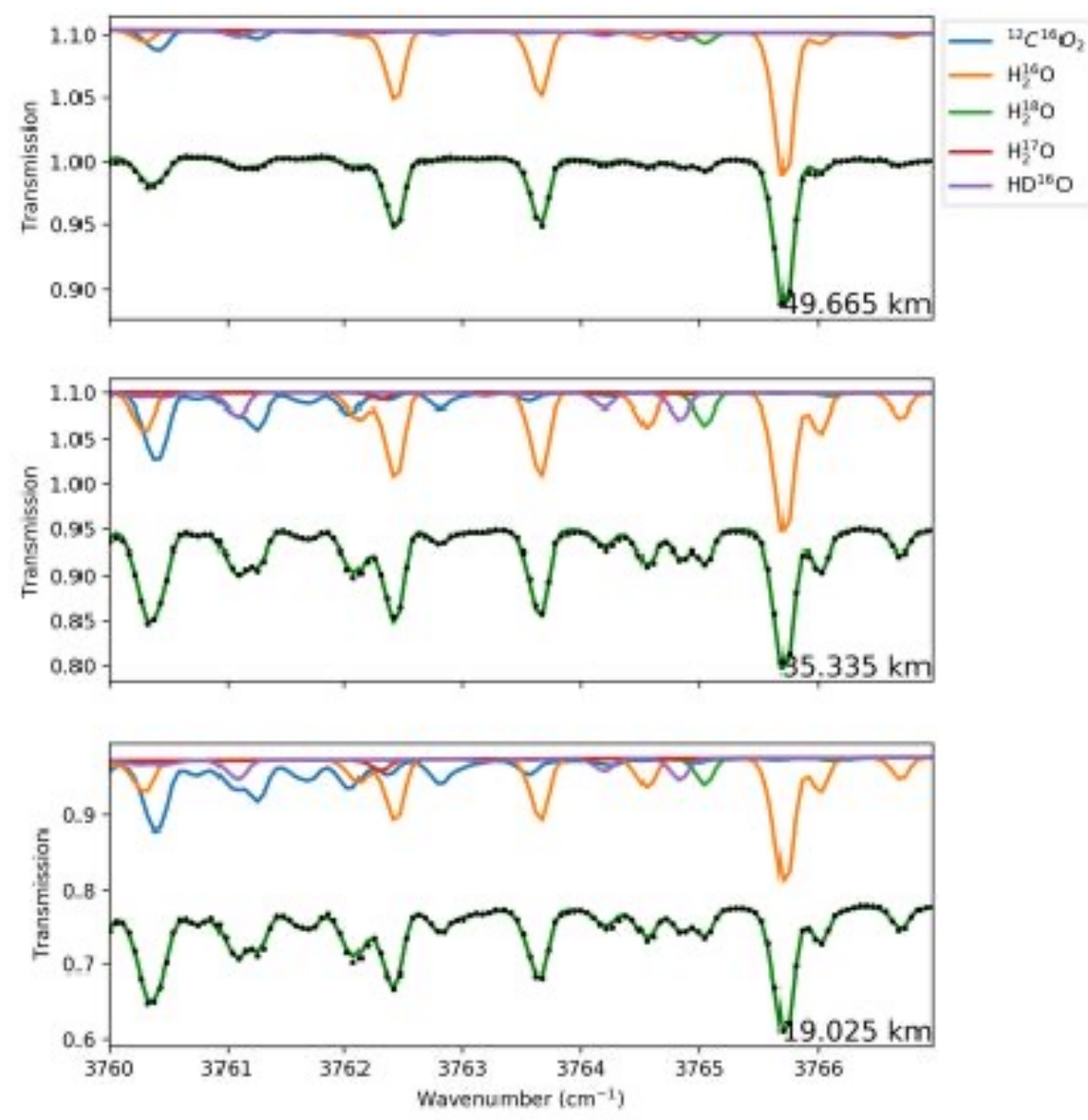

Figure 1: Example of one ACS MIR spectral window in diffraction order 224, measured at tangent heights of 19, 35 and $50 \mathrm{~km}$. The black dots represent the measured spectra, and the green line shows the best fit to the data. The contribution from each species to the spectra is also shown, following the colours in the legend.

\section{Radiative Transfer Analysis}

The analysis of the spectra is performed using the NEMESIS code [6], which works under the optimal estimation framework. In particular, for each solar occultation, we retrieve simultaneous vertical profiles of pressure, temperature and volume mixing ratio of the four main water isotopologues.

The pressure and temperature profiles can be constrained from the $\mathrm{CO}_{2}$ absorption lines under the assumption of hydrostatic equilibrium and a given $\mathrm{CO}_{2}$ volume mixing ratio profile, which we obtain from the Mars Climate Database [7]. In the case of the water vapour isotopologues, the volume mixing ratios can be constrained from the depth of the corresponding absorption lines, which are observed up to $60 \mathrm{~km}$ approximately.

The retrieval scheme is applied to all ACS MIR observations made with secondary grating positions 4 and 5 for a full Martian year, covering a wide range of latitudes, seasons, and local time, and 
enabling, for the first time, the study of the climatology of both the $\mathrm{O}$ and $\mathrm{H}$ isotopic ratios in Martian water vapour.

\section{Summary and Conclusions}

Vertical profiles of the isotope ratios in the four main water vapour isotopologues $\left(\mathrm{D} / \mathrm{H},{ }^{18} \mathrm{O} /{ }^{16} \mathrm{O}\right.$ and ${ }^{17} \mathrm{O} /{ }^{16} \mathrm{O}$ ) at the terminator are obtained using solar occultation measurements by the Atmospheric Chemistry Suite onboard ExoMars Trace Gas Orbiter.

The large coverage of ACS solar occultation measurements allows, for the first time, the analysis of the variations of the $\mathrm{O}$ and $\mathrm{H}$ isotopic composition of water vapour for a full Martian year.

\section{References}

[1] Owen, T., Maillard, J. P., de Bergh, C., and Lutz, B. L..: Deuterium on Mars: The abundance of HDO and the values of D/H, Science, 240, 1767 LP - 1767, 1988.

[2] Webster, C. R., Mahaffy, P. R., Flesch, G. J., Niles, P. B., Jones, J. H., Leshin, L. A., Atreya, S. K., Stern, J. C., Chrsitensen, L. E., Owen, T., Franz, H., Pepin, R. O., and Steele, A.: Isotope Ratios of $\mathrm{H}, \mathrm{C}$ and $\mathrm{O}$ in $\mathrm{CO} 2$ and H2O of the Martian Atmosphere, Science, 341, 260 LP - 263, 2013.

[3] Krasnopolsky, V.A., Maillard, J. P., Owen, T., Toth, R. A., Smith, M. D.: Oxygen and carbon isotope ratios in the martian atmosphere, Icarus, Vol. 192, Issue 2, 2007.

[4] Jakosky, B. M.: Mars Volatile Evolution: Evidence from Stable Isotopes, Icarus, 94, 14-31, 1991.

[5] Korablev et al.: The Atmospheric Chemistry Suite (ACS) of Three Spectrometers for the ExoMars 2016 Trace Gas Orbiter, Space Science Reviews, vol. 214, pag. 7, 2017.

[6] Irwin, P., Teanby, N., de Kok, R., Fletcher, L., Howett, C., Tsang, C., Wilson, C., Calcutt, S., Nixon, C., Parrish, P.: The NEMESIS planetary atmosphere radiative transfer and retrieval tool, Journal of Quantitative Spectroscopy and Radiative Transfer,109, 1136-1150.

[7] Forget, F., Hourdin, F., Fournier, R., Hourdin, C., Talagrand, O., Collins, M., Lewis, S. R., Read, P. L., and Huot, J-P: Improved general circulation models of the Martian atmosphere from the surface to above 80 km, Journal of Geophysical Research: Planets, 104, 24155-24175, 1999. 